\title{
A ARTE FIGURATIVA DE MESTRAS-ARTESÃS DO ALTO DO MOURA, CARUARU-PE, E OS SENTIDOS ESTÉTICOS E SENSÍVEIS SOBRE QUESTÕES DE GÊNERO ${ }^{1}$
}

\author{
A figurative art of master-artisans from Alto do Moura, Caruaru-PE, and the \\ aesthetic and sensitive meanings on gender issues
El arte figurativo de las maestras artesanas de Alto do Moura, Caruaru-PE, y los significados estéticos y sensibles en cuestiones de género

Ilzy Gabrielle Soares da Silva² Mário de Faria Carvalho ${ }^{3}$

\footnotetext{
1 Este artigo é decorrente do projeto intitulado 'Os sentidos estéticos e sensíveis que simbolizam a categoria 'gênero' na arte figurativa de mestras-artesãs do Alto do Moura, Caruaru-PE", desenvolvido sob a coordenação do segundo autor deste estudo no âmbito da Universidade Federal de Pernambuco, Centro Acadêmico do Agreste, e conta com financiamento da Fundação de Amparo à Ciência e Tecnologia do Estado de Pernambuco.

2 Graduanda em Design - Universidade Federal de Pernambuco - Centro Acadêmico do Agreste. Bolsista de Iniciação Científica - Fundação de Amparo à Ciência e Tecnologia do Estado de Pernambuco. Pesquisadora d'O Imaginário - Grupo de Pesquisas Transdisciplinares sobre Estética, Educação e Cultura (UFPE/CNPq) e do G-pense! ¿ - Grupo de Pesquisa sobre Contemporaneidade, Subjetividades e Novas Epistemologias (UPE/CNPq). E-mail: ilzygssoares@gmail.com. http://lattes.cnpq. br/2064202105632380. http://orcid.org/0000-0003-4279-9095.

3 Doutor em Sciences Sociales - Université René Descartes, Paris V, Sorbonne. Professor Associado Nível I do Núcleo de Design e Comunicação e Professor Permanente do Programa de Pós-graduação em Educação Contemporânea (Mestrado e Doutorado), ambos da Universidade Federal de Pernambuco, Centro Acadêmico do Agreste. Líder d'O Imaginário - Grupo de Pesquisas Transdisciplinares sobre Estética, Imaginário e Educação (UFPE-CNPq). E-mail: mariofariacarvalho@gmail.com. http://lattes.cnpq.br/9631923493264179. http://orcid.org/0000-0002-7071-2586.
} 


\section{RESUMO}

O presente estudo é uma análise estética, sensível e feminista da produção de artesanato em barro de uma mestra-artesã da comunidade do Alto do Moura, Caruaru, Pernambuco. O processo de análise e investigação refere-se às obras da mestra artesã Marliete Rodrigues, considerando que compreender as recorrências estéticas, sensíveis, simbólicas e subjetivas presentes na produção artística de mulheres artesãs pode evidenciar o imaginário que se constitui a partir das vivências socioculturais cotidianas das artistas sobre questões de gênero. A partir de dada dimensão fenomenológica, buscamos responder a perguntas como: Qual a centralidade dos elementos estéticos e sensíveis nas obras da artesã? Quais elementos de gênero e ligados ao cotidiano da comunidade são materializados através dos símbolos presentes nas obras analisadas? É possível caracterizar como feminista a estética que se desenvolve a partir do imaginário e é expressa em suas obras? Os resultados obtidos apontam que apesar de, à primeira vista, a obra da mestra parecer estar inscrita numa espécie de feminilidade compulsória, pelo uso recorrente de elementos ligados a flores, o recato no vestuário e as ações das mulheres retratadas, a obra de Marliete se revela dissidente ao propor sutis rupturas nas estruturas a partir das quais a arte em barro da comunidade do Alto do Moura é constituída.

Palavras-chaves: Estética Feminista; Gênero; Imaginário.

\section{Abstract}

The present study is an aesthetic, sensitive and feminist analysis of the production of clay handicrafts by a master-artisan from the community of Alto do Moura, Caruaru, Pernambuco. The process of analysis and investigation refers to the works of the master artisan Marliete Rodrigues, considering that understanding the aesthetic, sensitive, symbolic and subjective recurrences present in the artistic production of women artisans can evidence the imaginary that is constituted from the daily socio-cultural experiences of women. artists on gender issues. From a given phenomenological dimension, we seek to answer questions such as: What is the centrality of the aesthetic and sensitive elements in the artisan's works? Which elements of gender and linked to the daily life of the community are materialized through the symbols present in the analyzed works? Is it possible to characterize as a feminist the aesthetic that develops from the imaginary and is expressed in your works? The results obtained show that although, at first glance, the master's work seems to be inscribed in a kind of compulsory femininity, due to the recurrent use of elements related to flowers, modesty in clothing and the actions of the women portrayed, Marliete's work is reveals dissent by proposing subtle ruptures in the structures from which the clay art of the Alto do Moura community is constituted.

Keywords: Feminist Aesthetics; Gender; Imaginary.

\section{Resumen}

El presente estudio es un análisis estético, sensible y feminista de la producción de artesanías en arcilla por un maestro artesano de la comunidad de Alto do Moura, Caruaru, Pernambuco. El proceso de análisis e investigación se refiere a la obra de la maestra artesana Marliete Rodrigues, considerando que comprender las recurrencias estéticas, sensibles, simbólicas y subjetivas presentes en la producción artística de las artesanas puede evidenciar el imaginario que se constituye desde la cotidianidad 
sociocultural. experiencias de mujeres artistas en temas de género. Desde una determinada dimensión fenomenológica, buscamos dar respuesta a preguntas como: ¿Cuál es la centralidad de los elementos estéticos y sensibles en las obras del artesano? ¿Qué elementos de género y relacionados con la vida cotidiana de la comunidad se materializan a través de los símbolos presentes en las obras analizadas? ¿Es posible caracterizar como feminista la estética que se desarrolla a partir del imaginario y se expresa en tus obras? Los resultados obtenidos muestran que aunque, a primera vista, la obra del maestro parece estar inscrita en una especie de feminidad obligatoria, debido al uso recurrente de elementos relacionados con las flores, la modestia en la vestimenta y las acciones de las mujeres retratadas, la obra de Marliete es revela un disidente al proponer sutiles rupturas en las estructuras a partir de las cuales se constituye el arte de barro de la comunidad de Alto do Moura.

Palabras Clave: Estética feminista; Género; Imaginario. 


\section{INTRODUÇÃO}

As mulheres querem ser donas de sua própria vida, no sentido da necessidade de ter o poder de escolha para exercerem sua vocação, seja como profissional, mãe, pesquisadora, dona-de-casa ou mesmo no acúmulo de todas as funções simultaneamente (ALMEIDA, 2010, p. 55).

A produção artística de mulheres artesãs do Alto do Moura, Caruaru, Pernambuco, tem representado não apenas a visibilidade da arte local, mas tem sido voltada, igualmente, à reflexão de questões sociais complexas. Assim, ao mesmo tempo que mestras-artesãs têm apontado em suas produções inquietações para o fortalecimento de seus protagonismos, relevam mensagens implícitas sobre o imaginário que as cercam.

Cogitamos o estudo da produção de artesanato em barro de três mestrasartesãs da comunidade do Alto do Moura, Caruaru-PE, enquanto trajeto sobre as representações simbólicas da categoria "gênero" presentesneste universo.Acreditamos que a construção de saberes artístico-populares, a partir dessa produção feminina, pode reafirmar o conhecimento popular das artesãs em barro da comunidade do Alto do Moura sobre o cotidiano das questões de gênero e em relação ao papel da arte na significação deste assunto.

Consideramos que a compreensão das recorrências estéticas, sensíveis, simbólicas e das subjetividades presentes na produção artística de mulheres artesãs pode ressaltar o imaginário de vivências socioculturais cotidianas sobre questões de gênero. Essa premissa pode ser determinante na construção de uma atualizada agenda de estudos voltados à valorização do modo estético-sensível de pensar a relação entre mulher, arte e sociedade. O imaginário está na base das concepções de tempo e espaço, bases, por sua vez, de toda construção cultural, inclusive de gênero(s). Esse(s) é (são) construído(s) culturalmente e mediados pelo cotidiano aqui exemplificados nas produções das mestras-artesãs eleitas.

Com base nessas premissas, a presente pesquisa contempla algumas questões, em específico: Os símbolos contidos nas peças produzidas por mestrasartesãs da comunidade do Alto do Moura, Caruaru-PE permitem cogitar o modo pelo qual estas mulheres representam a categoria 'gênero'? Qual a centralidade dos elementos estéticos e sensíveis neste fazer artístico? Quais elementos de gênero e ligados ao cotidiano da comunidade são materializados através dos símbolos presentes nas peças analisadas? Nesse sentido, e com fundamento nas discussões teóricas sobre Estética, Sensibilidades e Gênero, esta pesquisa consisti em repensar as categorizações de gênero com base em premissas não-redutoras.

As mestras artesãs eleitas para este estudo foram Ernestina Antônia, Rosário de Carvalho e Marliete Rodrigues. Contudo, devido às condições impostas pela situação de pandemia à coleta de dados sobre as outras mestras, o processo 
de análise e investigação ficou restrito apenas à mestra Marliete Rodrigues. Assim sendo, os objetivos que norteiam o presente estudo são, especificamente, apresentar um inventário da produção de artesanato em barro da mestra Marliete Rodrigues, que possibilite refletir sobre as representações simbólicas da categoria "gênero"; identificar os principais sentidos estéticos e sensíveis presentes nessa produção; analisar as representações simbólicas da categoria gênero presentes na produção artística da mestra a partir da Estética e das Sensibilidades.

A partir das pesquisas de campo, das obras catalogadas e com base na entrevista realizada, passamos a observar em que medida a produção artística de uma artesã ressignifica os padrões sociais impostos e, ao mesmo tempo, constrói uma estética diferenciada em relação às questões de gênero. Elegemos o trabalho da mestra Marliete Rodrigues por apresentar uma linguagem que, a priori, não reforça comportamentos machistas, misóginos, sexistas e pornográficos típicos de uma linguagem heteronormativa. As implicações da pergunta "Por que não houve grandes mulheres artistas"? (NOCHLIN, 2016), nos lança a analisar como a mestra, dentro de seu contexto social, rompe, ainda que intuitiva e implicitamente, com determinadas barreiras de gênero, fazendo ecoar através de suas obras representações estéticas (DURAND, 2001) e sensíveis (GOMES, CARVALHO, 2020; MAFFESOLI, 1996) da categoria gênero (BUTLER, 2003).

Tomamos a análise da produção da mestra Marliete Rodrigues, fortemente marcada pelo imaginário e pela significação do papel da arte nos assuntos cotidianos do interior de Pernambuco e que a envolvem enquanto cerne e sujeita principal da presente pesquisa. A partir dela surgiram questões outras, tais como: Qual a centralidade dos elementos estéticos e sensíveis dessas obras? Quais elementos de gênero ligados ao cotidiano da comunidade são materializados através dos símbolos presentes nas obras analisadas? É possível caracterizar como feminista a estética que se desenvolve a partir desse imaginário e é expressa em suas obras?

O trajeto metodológico decorre da perspectiva fenomenológica (CARVALHO; CARDOSO, 2015). A fenomenologia a qual recorremos é descritiva, filosófica e interpretativa. A abordagem qualitativa, por entender que lida com interpretações das realidades sociais (GIL, 2008), foi instrumentalizada a partir da Teoria do Imaginário de Gilbert Durand $(2001 ; 2004)$ e das observações sobre estética e sensibilidades de Michel Maffesoli (1996; 1988). A coleta de dados se deu a partir da realização de uma entrevista, da observação não participante e do registro de imagens que auxiliaram na construção de um diário de campo. De tal modo, a análise de imagens foi organizada a partir da técnica de análise de imagem proposta por Carvalho (2019).

\section{ARTE DE MULHERES E A ESTÉTICA FEMINSTA}

O modo como as mulheres foram (e ainda são) retratadas nas obras de arte e a enorme quantidade de artistas homens que conhecemos em relação ao pequeno 
número de mulheres reconhecidas como artistas, na história da arte, faz refletir sobre o quão penoso foi (e continua a ser) o percurso que as mulheres perfizeram para ocupar tais espaços.

Para repensar o lugar que a mulher ocupou, ao longo do tempo, na história, deve-se considerar que a maioria delas, até o século XVII, eram analfabetas (ALMEIDA, 2010), o que contribuía para que fossem tomadas como submissas e inferiores. Isso evidencia que a educação feminina foi pensada a partir de um ponto de vista masculino, conforme afirma Almeida (2010). Assim, desde a sociedade feudal à moderna, as mulheres foram impedidas de desenvolver outras habilidades que não aquelas pertencentes ao ambiente doméstico, ficando limitadas ao espaço do lar. Por serem consideradas frágeis e nunca autônomas, precisavam viver sob a vigilância da família e de seus maridos (ASSIS, 2012).

Vale ressaltar que, mesmo não sendo retratadas como protagonistas ou autoras das principais obras de arte, as mulheres sempre tiveram os seus corpos constantemente expostos, parcial ou completamente despidos, em incontáveis representações artísticas ${ }^{4}$ (ALMEIDA, 2010). Durante toda a Idade Média as monjas, por exemplo, desempenharam uma função fundamental para a arte feita por mulheres, pois somente a elas era permitido o desenvolver de habilidades artísticas, de leitura e de escrita (ALMEIDA, 2010 apud SENNA, 2007).

Segundo Assis (2012), a história da arte, desde o Mundo Antigo até a Idade Moderna, não considerava as habilidades artísticas, intelectuais e sociais femininas. Acreditava-se que o único sexo capaz de herdar e transmitir o conhecimento artístico era o masculino, como afirmam Nochlin (2026) e Korsmeyer (2014). Sobre essa forma de pensar, as autoras pontuam o conceito do 'Grande Artista', como sendo aquele que detém, supostamente, a genialidade independente do contexto que influencia o seu êxito. Nochlin (2016) conduz à compreensão de que existe um senso hegemônico e masculinista de que as mulheres não possuem talento o suficiente para produções artísticas, uma vez que não existem, segundo ela, 'Grandes Mulheres Artistas' retratadas ou valorizadas pela história clássica da arte.

A partir do século XIX, apesar de tantas dificuldades que as impossibilitavam de ascender profissionalmente, mulheres resistiram, subvertendo tal lógica patriarcal, e se fizeram presentes em espaços antes exclusivos a pessoas do sexo masculino. Assis (2012) argumenta que muitas delas faziam uso de pseudônimos masculinos para expor suas obras, revelando a dificuldade que enfrentavam apenas por serem mulheres.

É importante destacarqueapesar de inúmeros registros sobrea participação das mulheres na história da arte, muitas vozes continuam silenciadas. Uma grande parte da "história da experiência e expressão do universo feminino" permanecem ocultas, o que se traduz numa perda irreparável uma vez que não temos mais acesso a essas produções (ASSIS, 2012). 
Ainda assim, mesmo vivendo por tanto tempo fortemente oprimidas, as mulheres experimentaram grandes e expressivas mudança em seu comportamento nas primeiras décadas do século XX (ALMEIDA, 2010). Os discursos dominantes sofreram alterações profundas provocadas pela mudança de percepção do olhar feminino. Significativas modificações foram sentidas em todos os campos de atuação e invenção humana e, consequentemente, na arte, como afirma Assis (2012). Nos anos 1960, por exemplo, nos Estados Unidos, através do fortalecimento da crítica feminista e das primeiras passeatas feministas exigindo maior visibilidade de mulheres artistas nos espaços de exposição, artistas feministas lançaram o que foi chamado de Arte Feminista ${ }^{5}$. A partir da década de 1970, o Movimento Feminista atuou como marco decisivo para a libertação da mulher (ASSIS, 2012). Tais mudanças permitiram que, aos poucos, as mulheres pudessem atuar e expandir seus horizontes, seja no mercado de trabalho, na vida intelectual e nas artes (ALMEIDA, 2010).

Portanto, como ressalta Bovenschen (1986), somente através de sua autonomia, participação política, ocupação de espaços públicos e de espaços de decisão é que as mulheres puderam, minimamente, conquistar e ascender a novos espaços, assim como desenvolver diferentes formas estéticas. A permanente luta por libertação de determinados padrões opressores de gênero pode ser lida, certamente, como o principal elemento propulsor do fazer artístico feminino nos últimos tempos.

\section{FUNDAMENTOS PARA UMA ESTÉTICA FEMINISTA}

Ao observarmos a trajetória da mulher na história da arte percebemos que ela foi um ser aceitável apenas como 'musa inspiradora' quando se trata do grande tema da arte canônica. Diante desse argumento e contexto, as mulheres artistas foram confrontadas com a difícil escolha de viver por sua arte ou se restringir apenas ao sexo (BOVENSCHEN, 1986). Para se pensar sobre a recorrência de uma estética feminista , deve-se considerar que o gênero, as identidades e a sexualidade misturam-se às complexidades dos processos de representação de caráter individual e coletivo, não permitindo generalizações sobre a atividade artística das mulheres (KORSMEYER, 2014). Nesse sentido, Meskimmon (2003) afirma que é preciso investigar a arte feita por mulheres buscando entender como ela une a diferença sexual em sua especificidade material e em seu lócus históricos particular, evitando responder apenas à perguntas como "o que é uma mulher artista" ou "o que é arte das mulheres".

Korsmeyer (2014) reflete que estudos nesse sentido devem descobrir se no trabalho criativo que as mulheres produzem opera algum tipo de estética feminista que contradiz, ainda que de forma clandestina ou implícita, um masculino normativo e dominante em termos culturais, tal como problematiza ao longo de sua obra. Para a autora, a formação e aplicação de ideias sobre obras de arte, criatividade e valor

5 Arte feminista é uma categoria de arte associada ao movimento feminista dos anos 1960-1970. Trata-se de uma manifestação política mobilizada no sentido de subverter a definição masculinista de arte, abordando temas como classe, raça, gênero e sexualidade 
estético, devem ser formuladas com atenção aos papéis que o gênero desempenha no processo inventivo, entendendo que as imagens, representações e expressões que se originam de ideias são indicadores de posição social e de poder (KOSRMEYER, 2014). No entanto, tais pressupostos não devem se restringir a referir, tão-somente, à existência de qualquer relação simplista e redutora entre o sexo do criador e o trabalho produzido, muito menos ao argumento de que a arte feita por mulheres tem algum tipo de "feminilidade" eterna (MESKIMMON, 2003).

Bovenschen (1986) considera que a arte com intenção feminista se refere à consciência estética e aos modos de percepção sensorial, tendo como característica fundamental a libertação da imaginação da mulher e a ruptura com as leis formais de um determinado meio, sempre tomado a partir de referenciais masculinistas. Nesse sentido, uma (outra) tradição e ruptura podem ser encontradas nas obras de artistas que compõem o movimento e debate feminista. É através de um processo de subversão, conquista, reivindicação, apropriação e formulação que se dá a produção artística das mulheres (BOVENSCHEN, 1986).

A estética feminista pode ser entendida, então, como "uma resposta visual a um conjunto muito específico de circunstâncias culturais e da história" (RAYMOND, 2019 , p. 40). Aqui, o termo feminista é entendido e assumido como uma força de ação política, que aponta para o ato político materializado em forma de imagem e que sugere um compromisso ético não apenas em relação aos sentimentos de uma pessoa acerca de si mesma, mas também com relação à outra, como aponta Raymond (2019).

A preocupação com as questões de gênero, classe social, etnia e raça, a utilização de bordado e costura, a desconstrução de estereótipos, e a recuperação histórica das mulheres na arte são tendências e aspectos éticos que caracterizam as artes visuais de caráter feminista, principalmente quando considerado o aspecto pósestruturalista que possuem, como afirma Tvardovskas (2015). São, em linhas gerais, produções marcadas pelas vivências e não apenas pela técnica.

Algumas artistas, por exemplo, recorrem ao nu feminino e aos materiais e suportes ligados ao trabalho manual e ao artesanato enquanto forma de provocação (ALMEIDA, 2010). Outras tecem críticas a ideais tradicionais de beleza, repudiando valores estéticos essencialistas da feminilidade ao experimentarem despertar nas(os) expectadoras(es) o nojo e outras emoções perturbadoras, questionando, contradizendo ou desmascarando os estereótipos ocidentais da identidade feminina (KORSMEYER, 2014). Assim sendo, o risco da forma, o contorno e o símbolo que compõem a imagem são os elementos que moldam a estética feminista (RAYMOND, 2019), tendo como característica "um elo indissociável entre arte e vida, entre arte e experiência, entre arte e produção de subjetividades" (STUBS; TEIXEIRA- FILHO; LESSA, 2018, p. 06).

No Brasil, as mulheres artistas reinventam, cotidianamente, as narrativas sobre masculino e o feminino, ironizando as práticas de poder e desconstruindo estereótipos misóginos, mesmo sendo poucas as que se autodenominam ou que consideram suas obras como genuinamente feministas (TVARDOVSKAS, 2015). Ainda 
assim, intuitiva e politicamente, elas criam outras representações para o corpo, o feminino e para as subjetividades a partir de uma poética insurgente e decorrente de uma postura ética, estética e gendrificada de resistência e da existência.

Portanto, a estética feminista capta e considera elementos que não estão ligados ao que é considerado como padrão ou universal, ao que está interligado apenas à figura masculina, o que não quer dizer que se restringe apenas ao universo feminino. Trata-se de uma estética enquanto existência, capaz de "gerar novas formas de ver, sentir, significar e existir" no mundo (STUBS; TEIXEIRA-FILHO; LESSA, 2018).

\section{DISCUSSÕES E NOTAS}

\subsection{GÊNERO E IMAGINÁRIO LOCAL: AS MEMÓRIAS E O ESPÍRITO INVENTIVO DE MARLIETE RODRIGUES}

O Alto do Moura, e sua produção artística em barro, é um importante centro difusor da cultura pernambucana. Famílias, através da comercialização de tal produção, garantem o desenvolvimento local e a promoção da arte de Pernambuco (FONSECA; DIAS; CAMPOS, 2017). Nesse sentido, Maffesoli (1996) destaca que a cultura de uma sociedade toma forma quando se manifesta exteriormente, que só assim ela passa a existir imagética e materialmente. A classe artesã da comunidade do Alto do Moura, sobretudo as mulheres, contribui para formar, manter viva e difundir a cultura do interior nordestino. A arte torna-se um processo de compartilhamento sensível do societal.

Marliete nasceu em 18 de setembro de 1957, na cidade de Caruaru, Pernambuco. Filha de avós e pais artesãos, a mestra teve contato com a arte em barro desde muito cedo, antes mesmo de ir para a escola brincava de modelar o barro quando confeccionava seus próprios brinquedos. É importante destacar que devido à vulnerabilidade socioeconômica das famílias dessa comunidade, as crianças precisavam trabalhar para complementar a renda familiar. A produção, segundo Marliete, era comercializada na Feira de Caruaru, reconhecida como patrimônio cultural imaterial do Brasil, em 2006. A confecção das peças era feita de forma seriada para atender às necessidades utilitárias do mercado capitalista. Com o tempo, seu irmão mais velho passou a acompanhar o pai na feira para vender os brinquedos em barro resultantes da produção das crianças da família. Nessa época, Marliete já estava na escola e narra que esperava ansiosa para modelar seus brinquedos em barro. Em entrevista concedida aos autores, a mestra relata:

Quando eu tinha 8 anos de idade, já estava na escola. Eu chegava e já vinha pensando em brincar com barro e aí já comecei a vender algumas coisinhas dos meus brinquedos. Tinha meu irmão que também fazia os brinquedinhos, que é o José Antônio. Ele fazia uns cavalinhos e sempre ia à feira com papai para tomar conta dos brinquedinhos da gente para vender. Papai vendia numa banquinha e ele forrava um papelzinho no chão para colocar os brinquedinhos 
da gente para vender. Todos os irmãos faziam brinquedinhos.

A fala de Marliete mostra como a comunidade, através da repetição de padrões heteronormativos, mantinham as mulheres restritas aos espaços domésticos (ASSIS, 2012), o que contribui para que fossem invisibilizada como artistas. Mesmo participantes de todo o processo produtivo mulheres não têm, na maioria das vezes, seus nomes associados às obras. Esta evidência aponta que nem sempre o trabalho feminino é considerado como artístico, o que impede o reconhecimento e as invizibiliza. O sutil processo de invisibilidade operado, nesse ponto, impede a legitimação da criatividade das mulheres quanto à produção artística.

A partir da observação da produção de sua irmã Socorro que, após a morte de seu pai, passa a ser a figura de referência artística para a mestra, surge em Marliete a vontade de desenvolver peças em miniatura, as ceninhas, que são a reprodução em barro de cenas cotidianas que permeiam o imaginário da mestra. Muitas dessas ceninhas envolvem as vivências que ela teve com sua mãe e avó paterna, como explica a mestra:

[...] comeceia desenvolver mais esse lado da miniatura e a criatividade porque eu gostei muito. E aí veio aquela vontade de tá sempre criando e comecei a fazer as ceninhas, comecei criando as ceninhas. Observar ceninha de família. Comecei imaginando uma vovozinha contando história para os netos [...], a vovó fazendo cafuné, a vovó fazendo crochê. Muitas coisas assim com as vovozinhas e também com as mães.

Na obra Minha avó Teresa, com seus netos, vendendo seus produtos, na Feira de Caruaru, Marliete dá forma à uma memória de sua mãe, já falecida, através de uma de suas ceninhas. Na obra, sua bisavó, artesã de louças, vende sua produção em barro (peças utilitárias para uso doméstico e, também, em tamanho reduzido, vendidos como brinquedo para crianças) na companhia de seus três netos (a mãe e tios da mestra) dos quais era responsável pela criação.

Figura 1: Minha avó Teresa com seus netos, vendendo seus produtos, na Feira de Caruaru

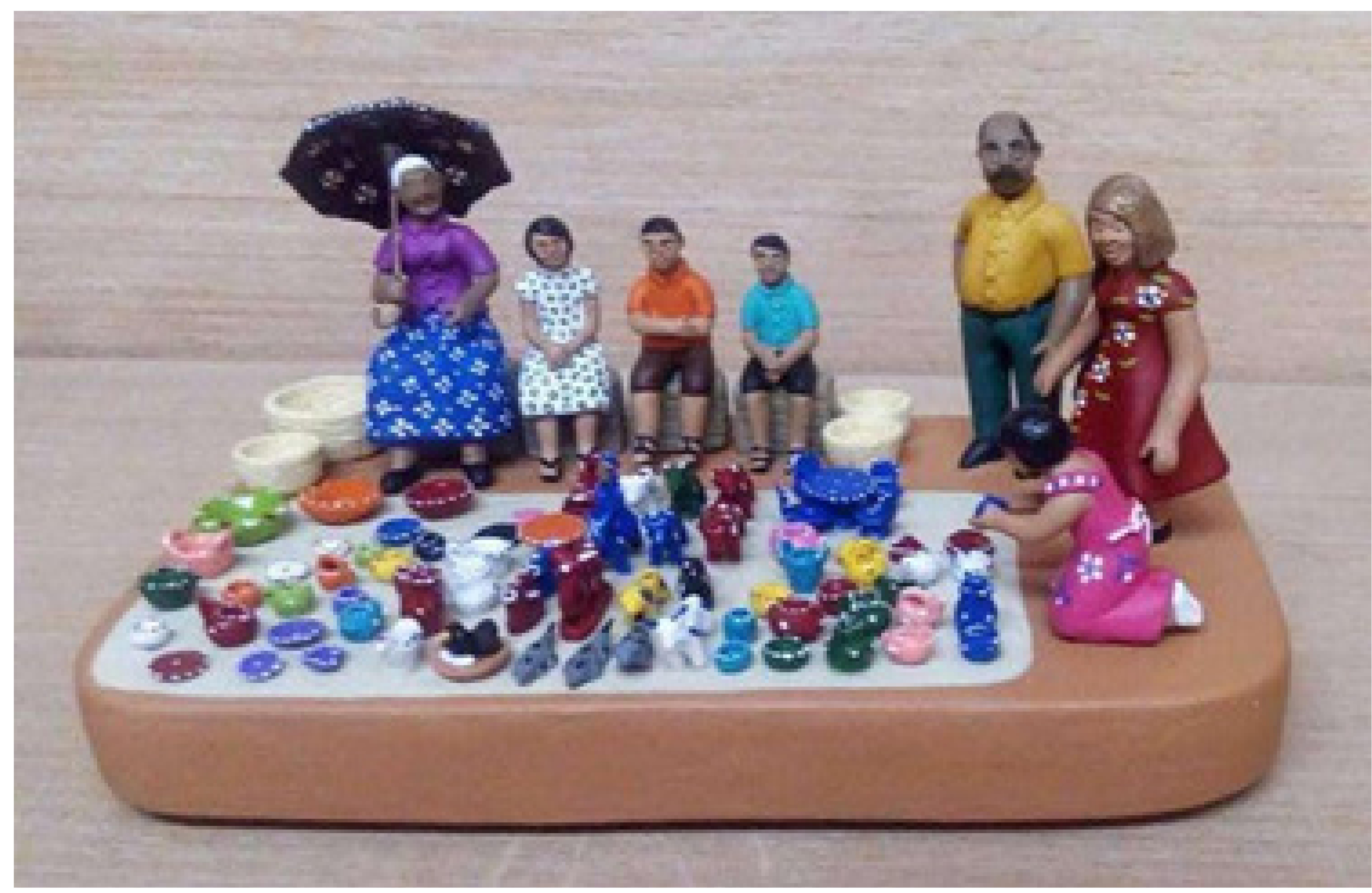

Fonte: Acervo Marliete Rodrigues 
Percebemos o quanto o imaginário local é sempre associado à ideia familiar na qual a arte feminina é utilizada para dar sustento à família e não entendida como arte em si mesma. A mulher, nessa lógica social, é vista como cuidadora e provedora de sua família, tão-somente.

Na obra acima, apesar de elementos como vestuário, penteados e postura dos personagens reforçarem alguns estereótipos de gênero, visto que retratam o cotidiano de uma comunidade no interior de Pernambuco fortemente marcada pelo machismo, podemos perceber algumas sutis subversões em relação à arte masculinista que opera no referido contexto. Marliete retrata uma criança de vestido rosa, com características que remetem ao feminino, ajoelhada escolhendo suas panelinhas em barro, cuidadosamente pintadas e decoradas, sob a supervisão de seus pais. As mulheres da cena parecem cuidadosas: a artesã olhando suas peças sendo manuseadas pela criança, pois depende da venda de cada uma delas para sobreviver; a mãe de braços abertos como se protegesse a criança. Nesse gesto da mãe da criança, percebemos uma referência às obras que retratam a Grande Mãe, Maria, de braços abertos em sinal de proteção, amparo, cuidado dos seus filhos. Ao retratar o corpo das mulheres, Marliete o faz como ele é, o corpo real, não idealizado para o deleite masculino (CARVALHO, 2019). As crianças que acompanham a avó estão quietas para não atrapalharem a venda. $O$ homem presente na cena tem uma postura passiva. Ainda que sua mão apoiada na cintura indique um certo grau de impaciência, ele permanece esperando sem interferir na escolha da criança.

Além da obra apresentar uma criança com elementos dito femininos como protagonista da cena, pois da escolha dela depende a venda do produto, Marliete insere a arte das louceiras como um resgate histórico dessas artesãs, evidenciando a recorrência de uma tendência típica de uma estética feminista (TVARDOVSKAS, 2015), reafirmando a relevância delas para a comunidade onde tal fazer artístico é menosprezado e invisibilizado. Ao observar a obra sou remetida ao meu tempo de criança onde brinquedos como esses fizeram parte do meu trajeto antropológico. Nascida e criada em Caruaru, pude vivenciar, ao brincar com essas panelinhas e animaizinhos em barro, que a experiência estética produzida por essas artesãs demonstra o quanto a arte dessas mulheres permeia o imaginário local e constitui as subjetividades de muitas pessoas.

Outra obra marcante de Marliete é As lavadeiras. Podemos observar mulheres lavando roupas e na responsabilidade de cuidar de crianças, uma cena típica de populações do agreste pernambucano. Apreendemos o quanto os rituais diários que cristalizam o gênero (BUTLER, 2003; NUÑEZ, 2019), exemplificado na obra pelo ato de lavar as roupas da família e do cuidado feminino, domesticam as mulheres e dificultam, muitas vezes, o exercício de outras funções senão às ligadas ao lar. A obra revela certa disruptura com a arte produzida na comunidade do Alto do Moura, onde a maioria dos artesãos retratam cenas cotidianas do universo masculino, sempre mediado pelo protagonismo masculino da cena. 
Figura 2: As lavadeiras

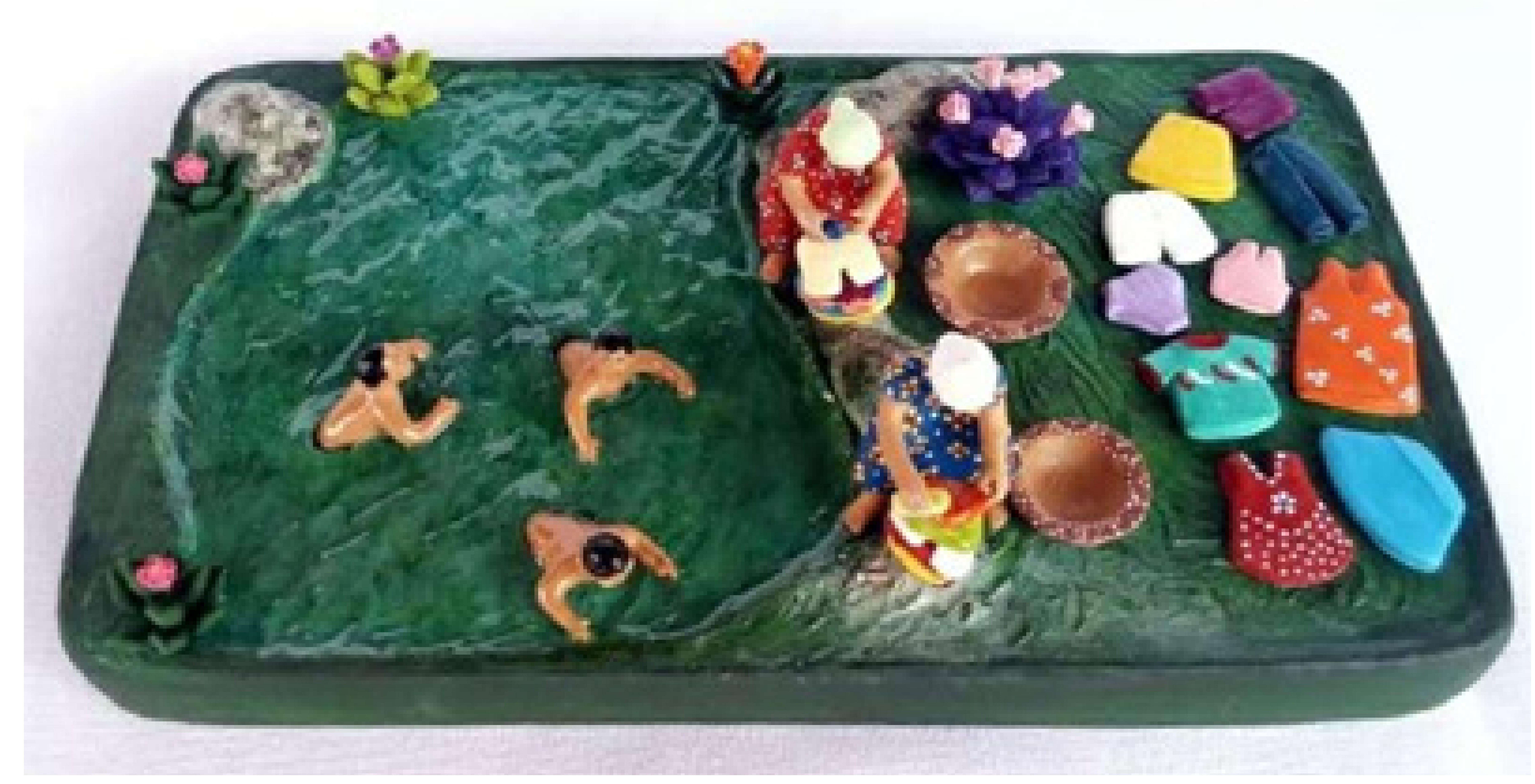

Fonte: Acervo Marliete Rodrigues

Linda Nochlin (2016) sugere que a produção artística demanda um longo período de experimentação e estudo de técnicas, além de envolver a busca por uma forma própria, coerente e sensível de linguagem. Ou seja, é preciso afeto e tempo para dedicar-se ao ofício da arte. Poderiam as mulheres dessa comunidade gozar de tanto tempo disponível se a elas é imposta toda a carga do trabalho doméstico, além de se esperar, também, que sejam responsáveis pelo sustento do lar? Sendo assim, como poderia uma mulher artesã, na incumbência quase que exclusiva de cuidar das(os) filhas(os) e afazeres domésticos tenha as mesmas condições de ascender a ponto de ser reconhecida como artista e possuir obras significativas?

Marliete, percorre uma trajetória pessoal e artística que destoa da vivência da grande maioria das mulheres de sua comunidade e isso se reflete no reconhecimento de sua arte. Além de fazer parte de uma família que valoriza a arte em barro, suas escolhas pessoais sempre colocam o seu fazer artístico como prioridade e isso permitiu que aprimorasse as técnicas de seu trabalho. Ao retratar mulheres atuando em espaços públicos e privados e incorporando elementos que demarcam essas vivências, Marliete se mostra imersa em uma dimensão estético-gestual com características típicas de uma estética feminista (TVARDOVSKAS, 2015), além de ajudar a contar a história das mulheres de sua comunidade, exaltando o seu lugar no mundo e o trabalho artístico feito por elas que, até hoje, continua invisibilizado.

As duas obras analisadas demonstram a presença de um elo indissociável entre vida, cotidiano, arte, experiência e produção de subjetividades quando Marliete, utilizando-se de sua percepção de mundo como mulher e artista, relata as vivências da comunidade em que vive, dando ênfase às vivências de mulheres que fizeram parte de sua vida (MESKIMMON, 2003).

As ceninhas apresentam uma narrativa sensível sobre o cotidiano feminino de quem precisa gerenciar seu tempo entre os afazeres diários que as domesticam para serem apenas do lar e o trabalho de manter financeiramente suas famílias através do seu fazer artístico no barro. 


\subsection{MARLIETE E AS FIGURAÇÕES ESTÉTICAS FEMINISTAS DO GÊNERO NA ARTE}

A árvore genealógica de Marliete possui muito mais referências de mulheres do que de homens. As matriarcas da família eram louceiras. No entanto, até certo ponto de sua vida, a artesã, mesmo que implicitamente, demonstra ter no seu pai e seu tio as únicas figuras de referência criativa, evidenciando como a lógica masculina sobre o gênio criativo (NOCHLIN, 2016) opera na manutenção de estereótipos de gênero e mantém as mestras vinculados ao 'gênio criativo' masculino. $O$ relato de Marliete nos confere certa dimensão de como tal apontamento fez parte de seu cotidiano:

Quando eu tinha mais ou menos 11 anos comecei fazendo as figurinhas, os bonequinhos, sempre imitando o que eu via papai fazer [juntamente com] meu tio Manoel Eudóxio que é irmão da minha mãe. A gente sempre copia o que tá vendo.

Aos 16 anos, Marliete perdeu seu pai e consequentemente, a pessoa responsável pelo processo de queima e venda das peças em barro. Em virtude dessa perda, a família passou a desempenhar, além da produção das peças, os trabalhos de venda e queima como forma de não enfrentar dificuldades financeiras e para não ser esquecidas(os) como artesãs(ãos). As memórias de Marliete revelam, mesmo que implicitamente, como os papéis de gênero, até então, moldavam seu fazer artístico e de sua família como um todo.

A perda de um referencial masculino e o deslocamento do olhar de Marliete para um referencial feminino protagonizado por sua irmã, Socorro, pode ser entendido como um marco para a (des)construção da identidade estética de Marliete. A mestra relata que sentiu a necessidade de experimentar, de fazer coisas diferentes do que tinha feito até então. Nota-se que começou a produzir figuras maiores, iguais às que seu pai fazia, permitindo-se, assim, a novas descobertas, na busca por sua identidade artística e o distanciamento do processo produtivo baseado na mera cópia. O fazer artístico da artesã desmistifica a ideia de que o único ser capaz de possuir um espírito inventivo é o homem (NOCHLIN, 2016; KORSMEYER, 2014).

Danielle Pitta (2017), afirma que através da imaginação conseguimos dar sentido ao mundo. Para a autora, podemos compreender ou analisar a partir da razão, mas somente pela imaginação é que damos significado ao que está à nossa volta, ou seja, é imaginando que compreendemos e conseguimos interpretar os simbolismos. É através da libertação de sua imaginação que Marliete se permite romper com as leis formais do meio no qual está inserida e experienciar a produção de uma estética a partir da união entre emoção, conhecimento, natureza e imaginário. Sua obra está relacionada à pluralidade da existência e ao compartilhamento de emoções, de vivências e de sentimentos (CARVALHO; CARDOSO, 2015). 
A obra de Marliete inclui também temas relacionados ao imaginário pernambucano. Amestra retrata as profissões, os símbolos religiosos e as manifestações folclóricas como o Maracatu, as Bandas de Pífano, o Reisado, as Festas Juninas, as brincadeiras de criança, entre outros temas que pertencem à cultura pernambucana. A mestra, cuidadosamente, compromete-se a retratar a presença das mulheres e a cultura nesses acontecimentos como formas plurais da vida.

Dentre as obras de símbolos religiosos, uma chama bastante atenção. A obra Nossa Senhora, Mãe de Jesus, amamentando, retrata o casal Maria e José enquanto ela, Maria, amamenta a sua criança. Numa representação sensível e cheia de significados para Marliete, a obra apresenta a Grande Mãe com uma pequena parte do seu corpo imaculado parcialmente desnudo. Ao contrário das várias e já citadas representações do corpo da mulher na arte, essa obra remete, agora, à sensação de aconchego (PITTA, 2017), do afago e compartilhamento do amor materno.

Figura 3: Nossa Senhora, mãe de Jesus, amamentando

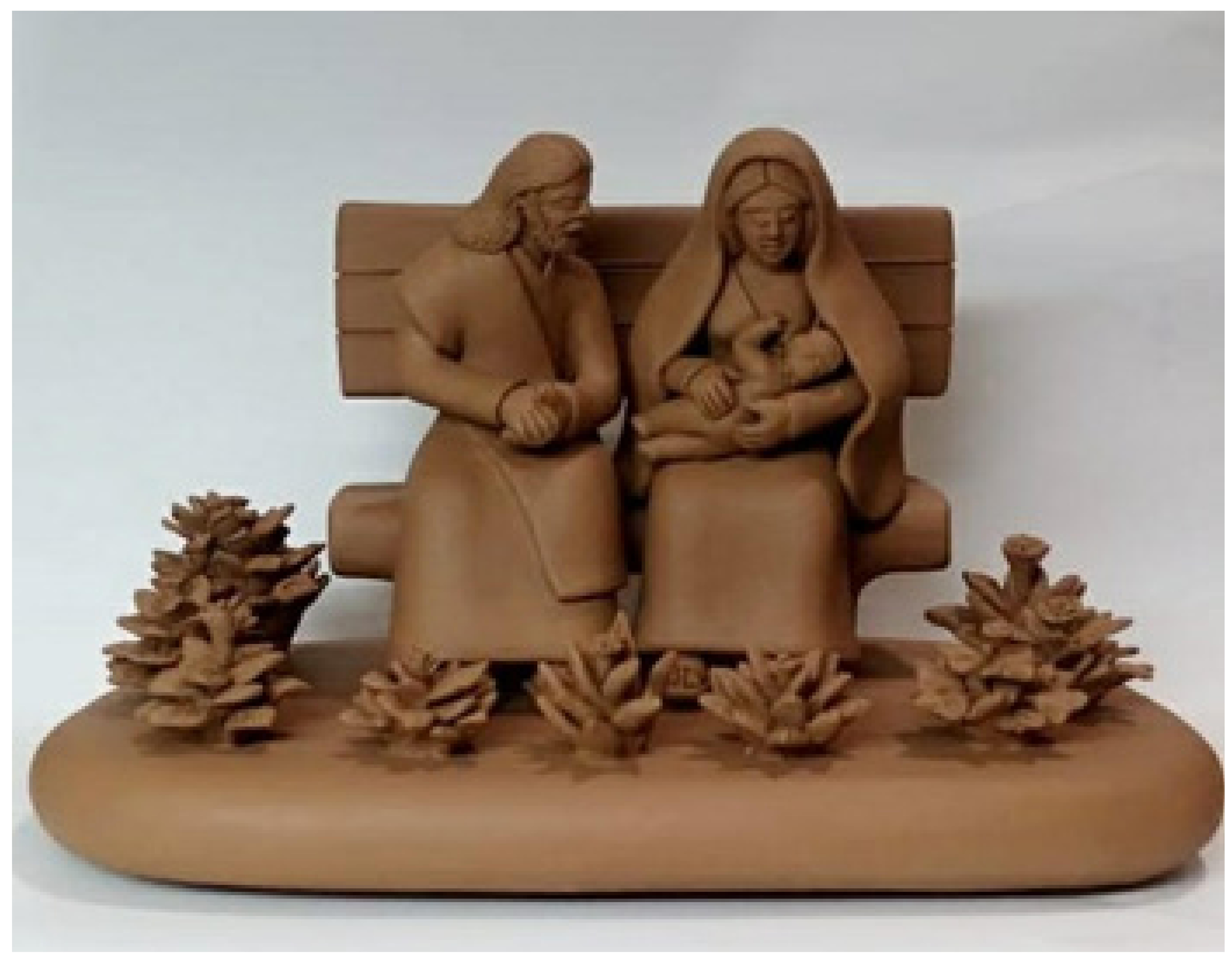

Fonte: Acervo Marliete Rodrigues

A Grande Mãe, recatada, cheia de pudor, se permite mostrar o seu corpo incorruptível para dar à sua criança o alimento que ela mesma é capaz de gerar. Marliete, ao moldar a mulher sagrada, que protagoniza a cena e cujo gestual ajuda a moldar os valores sociais marcados por noções heteronormativas sobre gênero e o papel social da mulher (ALMEIDA, 2010), rompe com as leis masculinistas da arte ao mostrar parte do corpo feminino não mais para o deleite do espectador, de forma erotizada ou como um objeto a ser consumido (CARVALHO, 2019) mas, revelando o deleite do momento que a mulher retratada experiencia enquanto amamenta sua criança ao mesmo tempo que desconstrói estereótipos misóginos ligados à amamentação. Os sentidos estéticos presentes na obra de Marliete podem ser entendidos como elementos de uma estética feminista quando, além de trazer uma nova representação do corpo das mulheres na arte, promove, ainda que sutilmente, uma reflexão sobre os estereótipos de gênero ligados às vivências das mulheres. 
É evidente, igualmente, que a mestra entende a importância de retratar o que ela nomeia de "a nossa História", ao se referir a elementos estéticos que compõem e a ajudam a narrar a história de Pernambuco, com destaca em:

\begin{abstract}
Eu jamais imaginei retratar coisas que não representassem a nossa História. Pra mim é tudo! Eu tenho uma paixão, um amor muito grande pelo meu estado de Pernambuco, pela minha cidade. Eu sou muito orgulhosa de ser daqui de Caruaru, do Alto do Moura. Pra mim é muita coisa, principalmente o Alto do Moura porque eu nasci e me criei aqui.
\end{abstract}

Percebemos que a arte produzida por Marliete é uma tradução gendrificada de suas experiências e de suas vivências. Mesmo que seu fazer artístico mantenha forte relação com o de sua família, na qual a produção de peças em barro tem estrita conexão com referências masculinas, suas obras apresentam, sutilmente, uma ruptura não apenas no comportamento imposto às mulheres, mas principalmente das mulheres artistas.

$\mathrm{Na}$ imagem abaixo, Marliete se autoretrata num momento de processo criativo em uma obra que está exposta no Museu do Barro , em Caruaru. Nos anos 1980, a mestra foi contratada pelo então presidente da Fundação de Cultura da cidade, Altair Porto, para produzir peças que ajudassem a contar a história da arte em barro e do agreste pernambucano. Durante quatro meses a produção da mestra foi voltada a reproduzir materialmente as subjetividades e vivências que fazem parte de seu trajeto antropológico e permeiam o seu imaginário. As obras passaram a compor a exposição permanente do museu. Isso reforça o que Nochlin (2016) comenta sobre a importância do papel das instituições seja para a visibilidade, quando permitem que as mulheres ocupem esses espaços, ou para a invisibilidade, quando ao menosprezarem a capacidade inventiva dessas mulheres baseados em estereótipos de gênero, negamse a abrir espaço para as artesãs.

Ao se autoretratar numa obra exposta no Museu do Barro ${ }^{6}$, em Caruaru, Marliete inscreve na história não apenas a si mesma, mas toda uma classe de mulheres artistas responsáveis pela criação, manutenção e difusão da cultura do interior de Pernambuco. Sua arte pode ser entendida como feminista (BOVENSCHEN, 1986) quando subverte a lógica de arte masculinista ao representar a vivência das mulheres de sua comunidade, quando conquista espaços em exposições e eventos até então exclusivos aos homens artesãos, ou quando reivindica a sua posição de mestra artesã, ao desconstruir estereótipos ligados ao gênero e ao contribuir para o surgimento de novas narrativas sobre o fazer artístico feminino do interior pernambucano. Através de suas ceninhas, a história das mulheres, continuamente invisibilizada, é contada, rompendo com os discursos dominantes de que mulheres não possuem espírito inventivo e de que não são capazes de produzir obras relevantes.

6 O Museu do Barro de Caruaru possui um acervo composto por peças utilitárias, decorativas, figurativas e ex-votos. Situado no Espaço Zé Caboclo, em homenagem ao artesão e pai de Maliete Rodrigues, o Museu articula a preservação e promoção das obras em barro produzidas no agreste pernambucano. 
Figura 4: Marliete trabalhando

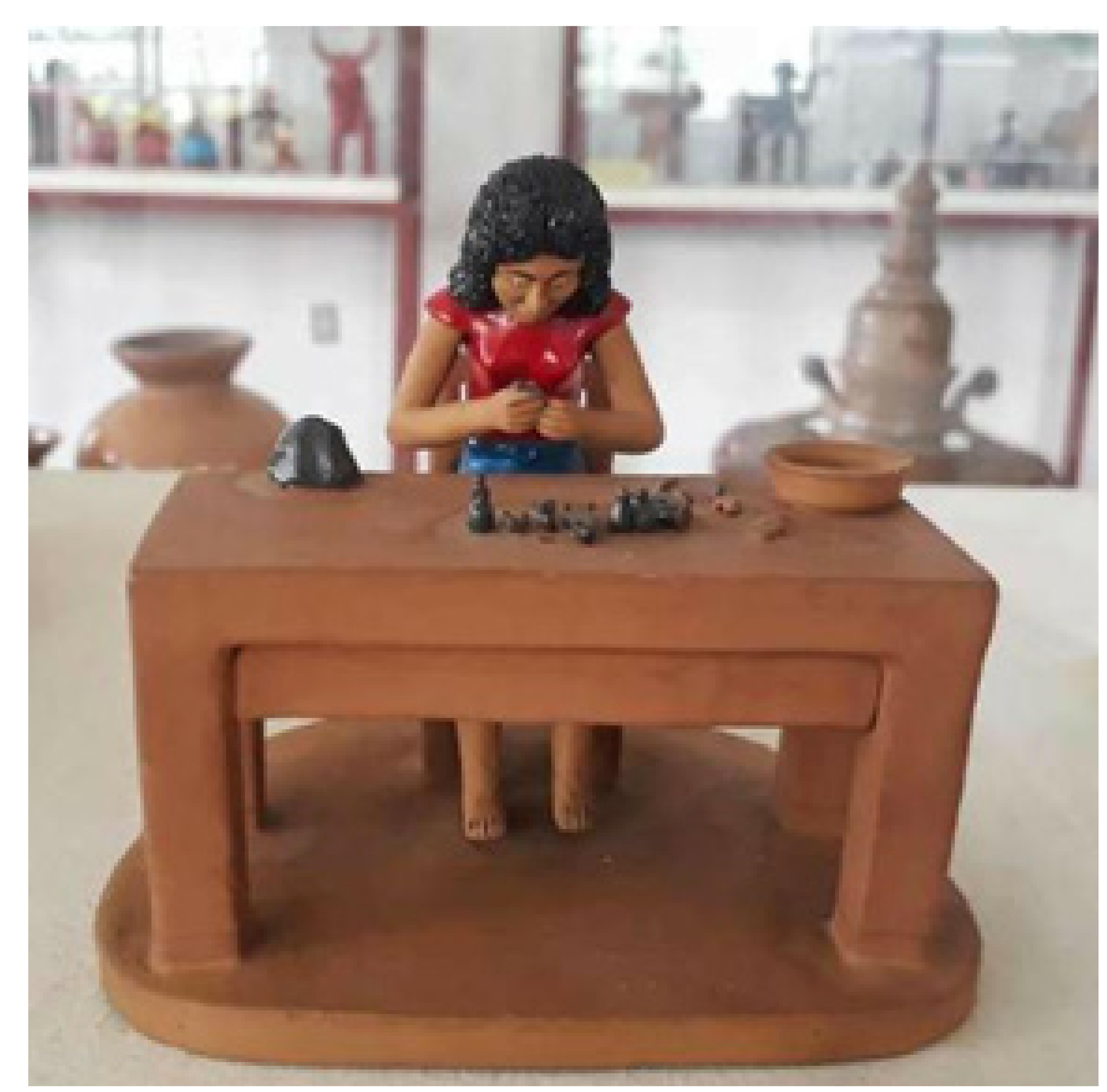

Fonte: Acervo Marliete Rodrigues

Para além da produção do barro que ressaltam a necessidade de preservar tudo que a mestra aprendeu sobre o fazer artístico de sua família e, particularmente, de seu pai e de sua irmã, Marliete busca transmitir o conhecimento adquirido ao longo dos anos para as próximas gerações, ensinando técnicas do fazer artístico feminino (e feminista) em barro e expondo obras de vários membros da família em seu ateliê, demonstrando que o título de Mestra Artesã corresponde à noção de mestra como uma pessoa que é guardiã das tradições culturais, preservando o saber coletivo (MELO, 2019).

\section{CONSIDERAÇÕES FINAIS}

Buscamos nesta pesquisa analisar a obra da mestra artesã Marliete Rodrigues a fim de identificar as recorrências estéticas presente em seu trabalho. Ainda que, à primeira vista, a obra da mestra pareça estar inscrita numa espécie de feminilidade compulsória, exemplificada aqui pelo recato das peças de vestuário e das ações das mulheres retratadas em suas ceninhas, a obra de Marliete Rodrigues se revela dissidente ao propor sutis rupturas nas estruturas sob as quais a arte em barro da comunidade do Alto do Moura é constituída.

Em sua obra, a artista narra a vivência da comunidade em que nasceu e cresceu, dando ênfase àquelas que, por mais que fossem sobrecarregadas de afazeres cujo propósito era sua domesticação ao lar, conseguiam produzir obras que fazem parte do imaginário local de muitas pessoas do interior pernambucano. Tal fato torna explícita a demarcação dos papéis de gênero presentes na comunidade na qual a mestra está inserida. Nesse sentido, Marliete pode ser entendida como uma 
artesã através da qual as mulheres, até então silenciadas, contam suas histórias, demonstrando que fizeram parte da construção artística e econômica da comunidade do Alto do Moura.

É através das obras em barro feitas pela mestra Marliete, a grande mãe de todo esse acervo de peças com significativa potência estética, histórica e sensível, que as vivências dessas mulheres podem ser contadas. É pelas mãos de Marliete, ao moldar o barro, traduzindo materialmente suas memórias e vivências, que as vozes dela e de tantas mulheres artesãs ecoam através do tempo, rompendo, assim, com o silenciamento a elas imposto ${ }^{7}$.

\section{REFERÊNCIAS}

ALMEIDA, Flavia Leme de. Mulheres recipientes: recortes poéticos do universo feminino nas artes Visuais. São Paulo: Editora UNESP; Cultura Acadêmica, 2010.

ASSIS, Sissa Aneleh Batista de. Mulheres Artistas: narrativas, poéticas, subversões e protestos do feminino na arte contemporânea paraense. 2012. 128 f. Dissertação (Mestrado em Artes) - Instituto de Ciências da Arte - ICA, Universidade Federal do Pará, Belém.

BOVENSCHEN, Silvia. Existe uma estética feminista? In: ECKER, Gisela. Feminist Aesthetics. 1. ed. Barcelona: Icaria Editorial, 1986. p. 21-58.

BUTLER, Judith. Problemas de Gênero: feminismo e subversão da identidade. Trad. Renato Aguiar. 2. ed. Rio de Janeiro: Civilização Brasileira, 2003.

CARVALHO, Mário de Faria; As performances contestatórias do Coletivo Monstruosas: exemplificação de transgressão na arte. No prelo, 2019.

CARVALHO, Mário de Faria; CARDOSO, Fernando da Silva. Contemporaneidade, Pesquisa Social e Imaginário. Revista Nupem, Campo Mourão, v. 7, n. 13, p. 105-117, 2015. Disponível em: http://fecilcam.br/revista/index.php/nupem/article/viewFile/793/603. Acesso em: 14 nov. 2019.

DURAND, Gilbert. As estruturas antropológicas do imaginário: introdução à arquetipologia geral. Tradução Hélder Godinho. 2. ed. São Paulo: Martins Fontes, 2001.

DURAND, Gilbert. 0 imaginário: ensaio acerca das ciências e da filosofia da imagem. Tradução Rennée Eve Levié. 3. ed. Rio de Janeiro: DIEFEL, 2004.

FONSECA, Fernanda; DIAS, Tânia; CAMPOS, Roberta. A divisão sexual do trabalho e as desigualdades sociais entre homens e mulheres na arte do barro no Alto do Moura - Pernambuco/Brasil. In: Anais... XXXI Congresso ALAS, 2017, Montevideo. Montevideo: Asociación Latino Americana de Sociología, 2017. v. XXXI.

GOMES, Graciele Maria Coelho de Andrade; CARVALHO, Mario de Faria. (2020). Por uma pedagogia do belo: educação, estética e sensibilidades. EccoS - Revista Científica, n. 53, e16647, 2020. doi: https://doi.org/10.5585/eccos.n53.16647.

KORSMEYER, Carolyn. Gender and aesthetics: an introduction. 1. ed. New York: Routledge, 2014. p. 1-9. 
MAFFESOLI, Michel. Elogio da razão sensível. Petrópolis: Vozes, 1998.

MAFFESOLI, Michel. No fundo das aparências. Petrópolis: Vozes, 1996.

MELO, Rosilene Alves de. Saberes e formas de expressão: patrimônio de todos nós. Formação de Mediadores de Educação Patrimonial. Fortaleza: [s. e.], 2019. Disponível em: https://cursos.fdr.org.br/pluginfile.php/416735/mod_resource/content/15/index.html. Acesso em: 30 jun. 2020.

MESKIMMON, Marsha. Women Making Art: history, subjectivity, aesthetics. 1. ed. Abingdon: Routledge, 2003. p. 1-3.

NOCHLIN, Linda. Por que não houve grandes mulheres artistas? Tradução de Juliana Vacaro. São Paulo: Edições Aurora, 2016.

NUÑEZ, Marcela Bautista. Movimentos de resistência entre gênero, arte contemporânea e educação. Educação, Artes e Inclusão, Santa Catarina, v. 14, n. 4, p. 248-270, dez., 2018. Disponível em: http://www.revistas.udesc.br/index.php/arteinclusao/article/view/11579. Acesso em: 27 abr. 2020.

RAYMOND, Claire. Pode haver uma estética feminista? Comunicação e Sociedade [online], v. 32, n. 32, p. 31-44, 2019. Disponível em: http://www.scielo.mec.pt/pdf/csoc/v32/ v32a02.pdf. Acesso em: 14 nov. 2019.

SENNA, Nádia. da Cruz. Donas da beleza: a imagem feminina na cultura ocidental pelas artistas plásticas do século XX. 2007. 212 f. Tese (Doutorado em Ciências da Comunicação) - Escola de Comunicação e Artes da Universidade de São Paulo, São Paulo.

STUBS, Roberta; TEIXEIRA-FILHO, Fernando Silva; LESSA, Patrícia. Artvismo, estética feminista e produção de subjetividade. Revista Estudos Feministas, Florianópolis, v. 26, n. 2, p. 1-19, 2018. Disponível em: <https://periodicos.ufsc.br/index.php/ref/article/ view/38901/37096 >.Acesso em: 14 nov. 2019.

TVARDOVSKAS, Luana Saturnino. Dramatização dos corpos: Arte contemporânea e crítica feminista no Brasil e na Argentina. 1. ed. São Paulo: Intermeios, 2015. 